\title{
Soroprevalência de pseudorraiva, peste suína clássica e brucelose em suínos do estado do Piauí
}

\author{
[Seroprevalence of pseudorabies, classical swine fever and brucellosis in \\ swine in the state of Piaui] \\ J.F.V. Braga' ${ }^{1}$, M.P.F. Teixeira', F.L.A.A. Franklin' ${ }^{2}$, J.A.T. Souza ${ }^{2}$, \\ S.M.M.S. Silva ${ }^{2}$, R.M.C. Guedes ${ }^{1} *$ \\ ${ }^{1}$ Escola de Veterinária - Universidade Federal de Minas Gerais (UFMG) - Belo Horizonte, MG \\ ${ }^{2}$ Centro de Ciências Agrárias - Universidade Federal do Piauí (UFPI) - Teresina, PI
}

\begin{abstract}
RESUMO
Este trabalho teve como objetivo determinar a soroprevalência de pseudorraiva, peste suína clássica (PSC) e brucelose suína em suínos do estado do Piauí, Brasil. Foram coletadas amostras sanguíneas de 384 suínos de criações intensivas e extensivas do estado. Anticorpos anti-Brucella spp. foram detectados pelo teste do antígeno acidificado tamponado e confirmados pelo teste 2-mercaptoetanol, enquanto a detecção de anticorpos contra os vírus da PSC e pseudorraiva foi realizada por ensaio imunoenzimático (ELISA), utilizando-se kits comerciais específicos. Anticorpos anti-Brucella spp. foram detectados em $1,04 \%$ (2/192) dos suínos de criações intensivas. Dos rebanhos avaliados, 0,78\% (3/384) dos animais exibiram anticorpos contra o vírus da PSC, sendo 1,04\% (2/192) de criações intensivas e 0,52\% (1/192) de criações extensivas. Anticorpos contra o vírus da pseudorraiva foram detectados apenas em suínos de criação extensiva, com prevalência de 5,2\% (10/192). Esses são os primeiros dados sobre a soroprevalência da brucelose suína, pseudorraiva e PSC em rebanhos do Piauí. A detecção de 10 amostras positivas para pseudorraiva causa preocupação sobre a possibilidade da circulação viral na população suídea desse estado e revela uma necessidade premente de realização de estudos mais extensos para melhor compreender a importância dessas enfermidades de notificação obrigatória em estados da região Nordeste brasileira.
\end{abstract}

Palavras-chave: suídeos, sorologia, Aujeszky, pestivírus, Brucella spp.

\begin{abstract}
This study aimed to determine the prevalence of Pseudorabies, Classical Swine Fever (CSF) and Swine Brucellosis in swine in the state of Piaui, Brazil. Blood samples were collected from 384 pigs from intensive and small outdoor systems in the state. Anti-Brucella spp. antibodies were detected by Buffered Acidified Antigen Test and positive results confirmed by 2-Mercaptoethanol Test. Detection of antibodies against CSF and Pseudorabies virus were performed by Enzyme-Linked Immunosorbent Assay (ELISA) using specific commercial kits. Only two samples (1.04\% - 2/192) from the intensive system were seropositive to Brucella spp. In the evaluated herds, $0.78 \%$ (3/384) of animals had antibodies against CSF virus, two from outdoor pigs (1.04\% - 2/192) and one from intensive systems (0.52\% - 1/192). Antibodies against the Pseudorabies virus were detected only in outdoor pigs, with seroprevalence of $5.2 \%$ (10/192). This is the first report on seroprevalence of Pseudorabies, CSF and Brucellosis in hog farms in Piauí, Brazil. The detection of 10 positive cases raises a concern regarding Pseudorabies virus circulation in the swine population in the state and reveals a need for further studies to better understand the real situation and status of obligatory notified diseases in the swine herds in the Northestern states of Brazil.
\end{abstract}

Keywords: suidae, serology, Pseudorabies, Pestivirus, Brucella spp.

Recebido em 19 de maio de 2012

Aceito em 15 de março de 2013

*Autor para correspondência (corresponding author)

E-mail: guedesufmg@gmail.com 


\section{INTRODUÇÃO}

A suinocultura brasileira ocupa, hoje, a quarta posição no ranking mundial de produção e exportação de carne suína, consequência de estudos e investimentos nesse setor da pecuária do país (Mapa, 2011). Entretanto, uma das principais barreiras para o comércio internacional da carne suína brasileira para mercados exigentes é a ocorrência de enfermidades de notificação obrigatória e de importância econômica no país. Entre elas, citam-se pseudorraiva (doença de Aujeszky), peste suína clássica e brucelose.

A pseudorraiva, ou doença de Aujeszky, destacase por ser altamente contagiosa e por gerar impacto econômico em razão do elevado índice de letalidade em leitões e das barreiras sanitárias à exportação de carne suína (Murphy et al., 1995; Bascuñana et al., 1997), sendo, por isso, de notificação obrigatória pela Organização Mundial de Saúde Animal (Brasil, 2009). Essa doença é causada pelo herpesvírus suíno 1 (SuHV-1), membro da família Herpesviridae, subfamília Alphaherpesvirinae, gênero Varicellovirus, que possui apenas um sorotipo (Murphy et al., 1995; Pomeranz et al., 2005) e diferentes genótipos. Enquanto animais jovens apresentam, principalmente, sinais neurológicos e elevada letalidade, suínos mais velhos exibem alta morbidade, com predominância de sinais respiratórios e transtornos reprodutivos. Quando os animais afetados sobrevivem, tornam-se uma fonte de infecção quando há reativação do vírus devido à imunossupressão (Pomeranz et al., 2005).

Outra enfermidade viral altamente contagiosa e economicamente significativa é a peste suína clássica (PSC). A doença é causada por um Pestivirus, membro da família Flaviviridae, e sua severidade depende da virulência dos isolados envolvidos, além de outros fatores (Maxie e Youssef, 2007). Em rebanhos afetados por isolados de alta virulência, há alta taxa de morbidade e mortalidade, enquanto naqueles cujos isolados apresentam baixa patogenicidade, apenas transtornos reprodutivos podem ser vistos, como baixo desempenho ou falha reprodutiva representada por abortos, natimortos, leitões com tremor congênito ou malformações de órgãos viscerais e do sistema nervoso central. Os animais infectados podem ser assintomáticos, mas persistentemente infectados (Classical..., 2007). No Brasil, atualmente, são considerados livres de PSC os estados das regiões Sul, Sudeste e Centro-oeste, além dos estados de Tocantins, Bahia, Sergipe e Rondônia. Os estados do Nordeste do Brasil são a próxima meta para o programa nacional de erradicação dessa enfermidade, sobretudo devido à sua localização geográfica e à ausência de fronteiras secas com outros países.

A brucelose suína, causada pela bactéria Brucella suis, também é economicamente importante em razão dass perdas reprodutivas que gera (Porcine..., 2007), representadas, principalmente, por abortos em qualquer momento da gestação, nascimento de leitões fracos e natimortos (Lopes et al., 2010). No Brasil, pesquisas sobre essa doença são escassas (Poester et al., 2002), apesar da importância da brucelose em criações domésticas devido à característica zoonótica (Oslen, 2010).

No estado do Piauí, quarto maior produtor de suínos no Nordeste, dados referentes ao manejo e à sanidade de suínos são escassos, obscurecendo a situação sanitária do rebanho e evidenciando a necessidade de estudos sobre esse setor da pecuária. $\mathrm{O}$ conhecimento do status dessas enfermidades não tem apenas importância econômica, mas também em saúde pública, uma vez que pode direcionar e viabilizar a adoção de medidas de controle e profilaxia, diminuindo os prejuízos financeiros e o risco de transmissão zoonótica acarretados por essas enfermidades. Esse risco exacerba-se na população do estado, pois sabe-se que parcela significativa dos abates de suínos é realizada clandestinamente, sob precárias condições higiênicas, e cuja carne chega ao consumidor sem qualquer inspeção sanitária.

Não existem relatos sobre a soroprevalência da pseudorraiva, peste suína clássica e brucelose em suínos do estado do Piauí. Diante do exposto e da necessidade do conhecimento da real situação dessas enfermidades na população suína no estado, este estudo teve como objetivo determinar o status sorológico de rebanhos suinícolas criados sob manejos intensivo e extensivo com relação à pseudorraiva, peste suína clássica e brucelose, no estado do Piauí. 


\section{MATERIAL E MÉTODOS}

Durante o período de agosto de 2010 a março de 2011, 384 suínos pertencentes a rebanhos do estado do Piauí foram avaliados, sendo definido o número de amostras utilizado considerando-se um intervalo de confiança de $95 \%$, margem de erro de $10 \%$ e prevalência esperada de $50 \%$, uma vez que não há estudos prévios sobre quaisquer dessas enfermidades no estado (Mejia, 1973). Todas as amostras foram coletadas durante o abate dos animais, quando era verificada a origem do ponto de vista do sistema de criação. A rastreabilidade específica dos animais, com identificação da propriedade, não foi possível em suínos de criação extensiva e apenas em um número reduzido de animais de criação intensiva. Isso ocorreu devido ao fato de que a maioria dos suínos provenientes de diferentes criações intensivas eram transportados juntos em caminhões ao local de abate, onde não mais era possível a identificação da granja de origem.

Durante a sangria do animal, foram coletados $8 \mathrm{~mL}$ de sangue em tubos sem anticoagulante para posterior centrifugação e obtenção do soro. Esse soro era, então, armazenado em microtubos e conservado a $-20^{\circ} \mathrm{C}$ até o momento da realização dos testes sorológicos. As amostras dos animais de criação intensiva foram provenientes de oito propriedades e coletadas em frigorífico sob inspeção municipal ou sem inspeção, enquanto as amostras de suínos criados extensivamente, oriundos do interior do estado, foram obtidas apenas em abatedouros sem inspeção sanitária.

A detecção de anticorpos contra o vírus da PSC foi realizada por ensaio imunoenzimático (ELISA) de bloqueio, utilizando-se o kit IDEXX CSFV Antibody Tests (IDEXX HerdChek), enquanto os anticorpos anti-gpl do vírus da pseudorraiva foram detectados por ELISA screening, utilizando-se o kit IDEXX PRV/ADV gB Ab Test (IDEXX HerdChek), ambos de acordo com as recomendações do fabricante. Para detecção de anticorpos anti-Brucella spp., as amostras foram submetidas à triagem utilizando-se o teste do antígeno acidificado tamponado (AAT) e, quando observada aglutinação macroscópica, foram consideradas sororreagentes. As amostras positivas no teste AAT eram confirmadas pelo teste 2- mercaptoetanol (2-ME) (Alton et al., 1988), sendo consideradas sororreagentes aquelas com formação de grumos de precipitado e sobrenadante límpido. Foram consideradas verdadeiramente positivas apenas as amostras que reagiram a ambos os testes sorológicos.

\section{RESULTADOS}

Dos animais estudados, 192 pertenciam a rebanhos de criação intensiva e 192 eram criados extensivamente. As criações intensivas caracterizavam-se por suínos criados em regime permanente de confinamento em gaiolas ou baias e alimentados com ração, enquanto nas criações extensivas, os animais viviam soltos, buscavam seu próprio alimento ou alimentavam-se de restos de refeições fornecidos pelo proprietário.

Os resultados obtidos neste estudo estão demonstrados na Fig. 1 e são os primeiros relatos sobre a soroprevalência da pseudorraiva, peste suína clássica e brucelose em suínos do estado do Piauí.

Anticorpos para o vírus da pseudorraiva foram detectados em 2,6\% (10/384) dos suínos avaliados. Apenas os animais de criação extensiva exibiram anticorpos para o agente, com prevalência de 5,2\% (10/192) nesta subpopulação, enquanto os suínos criados intensivamente não foram sororreagentes (0/192). A rastreabilidade final não foi possível nos animais positivos por tratar-se de suínos de criação extensiva, os quais eram levados ao abate sem registro de produtor.

A prevalência de anticorpos anti-Brucella spp. foi de $0,52 \%(2 / 384)$, pois, apesar de três animais terem sido positivos ao AAT, apenas duas dessas amostras foram confirmadas ao 2-ME. Os dois suínos soropositivos pertenciam a criações intensivas; logo, a soroprevalência nesta subpopulação foi de 1,04\% (2/192). Os suínos de criações extensivas estudados não foram sororreagentes aos testes. Infelizmente, apesar de se estar seguro de que estes animais eram provenientes de criatórios intensivos, não foi possível rastrear a propriedade devido à mistura de animais provenientes de diferentes propriedades de criação intensiva em um mesmo veículo de transporte até o local de abate, como mencionado anteriormente. 


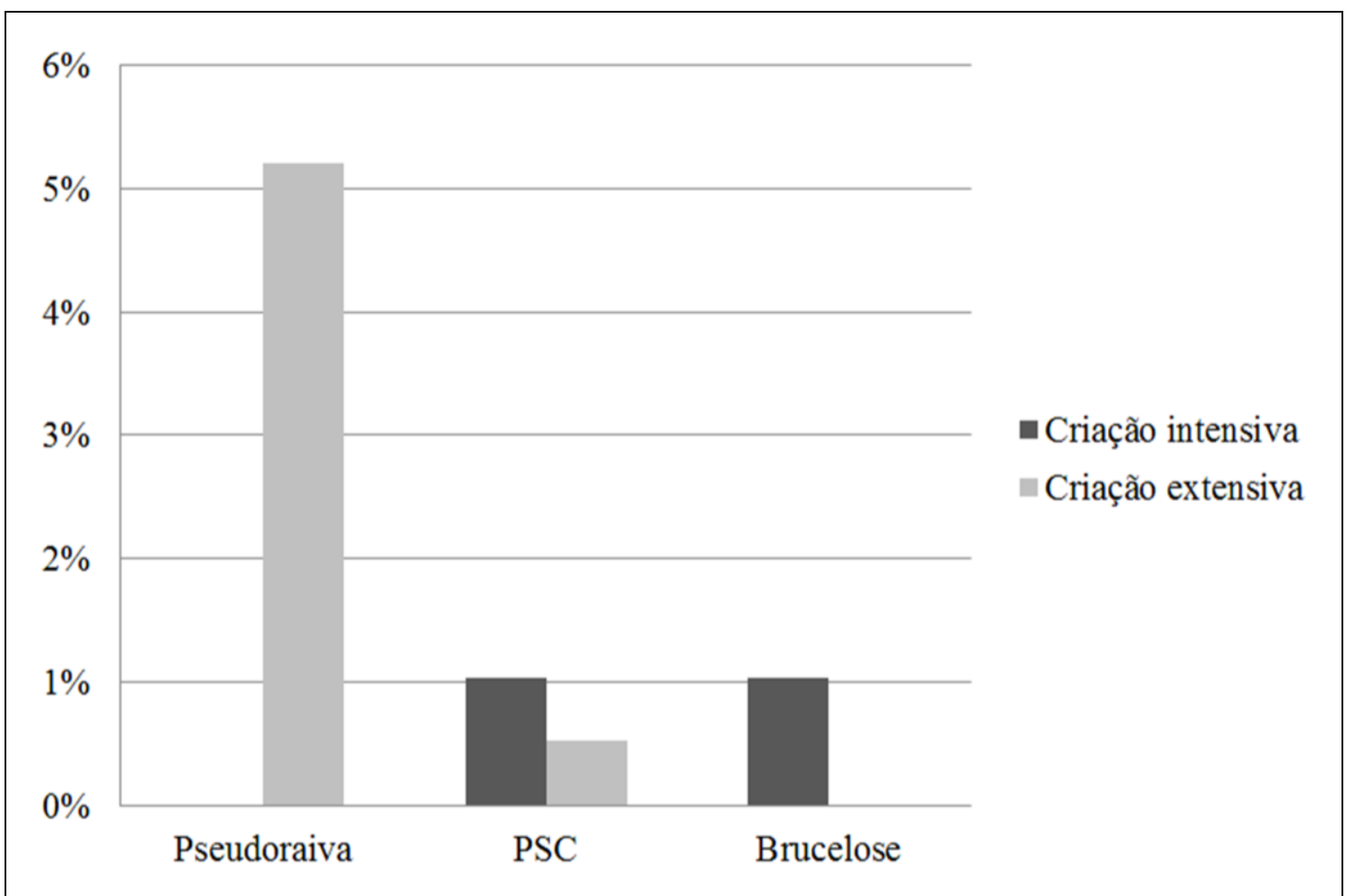

Figura 1. Prevalência de pseudorraiva, peste suína clássica (PSC) e brucelose em suínos de criação intensiva e extensiva no estado do Piaú, Brasil.

A soroprevalência do vírus da PSC nos suínos avaliados foi $0,78 \%$ (3/384). Anticorpos contra o agente foram detectados em $1,04 \%$ (2/192) dos animais de criação intensiva estudados, enquanto nos suínos criados extensivamente, a soroprevalência foi $0,52 \%$ (1/192) e uma amostra permaneceu como suspeita, mesmo após a repetição do teste. Não foi possível, novamente, a rastreabilidade final destes animais pelo mesmo motivo exposto acima, como também não foi possível viabilizar a confirmação final de positividade destes animais por soroneutralização, que somente é executada em laboratório oficial do Ministério da Agricultura, Pecuária e Abastecimento (Mapa), em Recife, Pernambuco.

\section{DISCUSSÃO}

Este estudo revela a circulação do SuHV-1 no estado do Piauí. No Brasil, focos da enfermidade foram registrados nos estados de Minas Gerais, Rio de Janeiro, Paraná, Santa Catarina e Rio Grande do Sul (Fonseca Júnior, 2008). Apenas os suínos de criação extensiva exibiram anticorpos para o vírus, evidenciando a circulação do agente nessa população de animais. Até onde se pode avaliar na literatura, o único estudo envolvendo animais de agricultura familiar disponível, realizado no estado de Rondônia, revela resultados distintos, uma vez que não foram detectados anticorpos para o vírus da pseudorraiva na população suinícola avaliada (Aguiar et al., 2006). A espécie suína é considerada o principal reservatório do vírus da pseudorraiva e o seu mais importante disseminador (Souza et al., 2002); logo, animais infectados de criação extensiva são potenciais fontes de infecção para suínos de produção intensiva, uma vez que precárias medidas de biossegurança são adotadas na maioria das granjas do estado, bem como fonte de infecção para outras espécies domésticas e silvestres. É importante ressaltar que a pseudorraiva, assim como a PSC, são enfermidades contempladas no Programa Nacional de Sanidade Suídea (PNSS), no qual constam os planos de contingência que especificam as medidas a serem adotadas em todo o território nacional no caso da ocorrência da doença em suídeos, visando à sua imediata eliminação (Brasil, 2009). 
A ausência de anticorpos para o SuHV-1 nos suínos de criação intensiva deste estudo não surpreende, já que as granjas incluídas no estudo não relataram qualquer sinal clínico sugestivo da doença e não possuíam histórico de vacinação contra pseudorraiva. Estudos outros de soroprevalência para pseudorraiva em sistemas de criação intensiva em São Paulo (2,6\%, São Paulo et al., 1986) e região do em torno de Goiânia (Souza et al., 2002) demonstraram baixos índices de positividade, 2,17\% (18/829) e 2,6\%, respectivamente, mas superiores à negatividade total observada no Piauí. Estes resultados indicam que, aparentemente, os sistemas de criação intensiva de suínos piauiense apresentam resultados sanitários melhores que outros estados em relação à pseudorraiva.

As diferentes soroprevalências do SuHV-1 observadas nos suínos de criação intensiva e extensiva deste estudo evidenciam as variações que podem ocorrer entre os patógenos circulantes nas diversas subpopulações suínas e enfatizam a importância do controle do abate clandestino, uma vez que essa prática inviabiliza a inspeção animal e o reconhecimento das enfermidades prevalentes na população suinícola, não havendo, consequentemente, adoção de medidas de controle que evitem a disseminação da doença para suínos ou, em caso de patógenos zoonóticos, para o homem.

A soroprevalência do vírus da PSC observada neste estudo encontra-se abaixo da especificidade do teste sorológico empregado, que é de 99\% (Blome et al., 2006). Atualmente, em casos como este, o Ministério da Agricultura, Pecuária e Abastecimento (Mapa) tem recomendado a adoção de procedimentos de investigação epidemiológica complementar para confirmar a ocorrência da enfermidade. Tais procedimentos incluem a identificação e interdição das propriedades de origem dos animais soropositivos, coleta de novas amostras para sorologia pareada, com eutanásia e necropsia de animais sororreagentes. Desses animais são coletadas amostras de tecido, como baço, linfonodo e tonsila, para isolamento viral, e os demais suínos são inspecionados clinicamente uma vez por semana, até que as evidências clínicas, epidemiológicas e laboratoriais obtidas permitam concluir se há ocorrência da doença ou trata-se de resultados falso-positivos com a negatividade da neutralização viral
(Borges, 2012 - Ministério da Agricultura, Pecuária e Abastecimento. Comunicação pessoal). Infelizmente, não foi possível a rastreabilidade dos suínos analisados neste estudo, o que inviabiliza a adoção dos procedimentos recomendados pelo Mapa e evidencia a importância de triagem regular das doenças de notificação obrigatória em rebanhos de criação intensiva e extensiva do estado.

É importante ressaltar que animais de criações extensivas têm maior probabilidade de adquirir a infecção, uma vez que surtos da doença comumente têm início quando suínos domésticos entram em contato com material infectado originado de porcos silvestres (Santos, 2002), o que pode ocorrer com frequência em criações extensivas. Além disso, um fator predisponente relevante para a infecção é a alimentação de suínos domésticos ou selvagens com restos de alimentação humana, típica desse tipo de criação suinícola (Santos, 2002). Sabe-se que criações extensivas de suínos são comuns na região Nordeste do Brasil, onde oito focos de PSC ocorreram em 2006 nos estados do Ceará e Paraíba (Anônimo, 2006, citado por Ferrer et al., 2010), em 2007 no Ceará (Anônimo, 2007, citado por Ferrer et al., 2010) e no ano de 2008, no estado do Maranhão (Análisis..., 2008). Aguiar et al. (2006) não detectaram amostras reagentes ao PSC em suínos provenientes de agricultura familiar em Rondônia, região Norte do país. Resultados semelhantes foram obtidos por Lima (2010), ao estudar 120 fêmeas com problemas reprodutivos em 27 granjas da região Sul, onde não houve animais soropositivos para PSC. Esses resultados corroboram Gomes (2009), que considera os estados de Rio Grande do Sul, Santa Catarina, Paraná, São Paulo, Minas Gerais, Mato Grosso do Sul, Mato Grosso, Goiás, Tocantins, Rio de Janeiro, Espírito Santo, Bahia, Sergipe e Distrito Federal como áreas livres de PSC no Brasil.

Anticorpos anti-Brucella spp. foram detectados apenas em três animais de criação intensiva, entretanto esse percentual encontra-se dentro da margem de erro do AAT, cuja sensibilidade é de $88 \%$ (Praud et al., 2012). Sabe-se que baixos títulos de aglutininas podem ser detectados na maioria dos rebanhos, mesmo que os animais não estejam infectados (Porcine..., 2007), e, embora o AAT seja considerado a melhor alternativa para o diagnóstico em massa de rebanhos 
(Organización..., 1986), não é recomendado para áreas de baixa prevalência (Motta et al., 2010), uma vez que apresenta alta sensibilidade e baixa especificidade, podendo ocorrer reações cruzadas com Yersinia enterocolitica e Brucella spp. (Jungersen et al., 2006). Na região Nordeste, resultados semelhantes foram obtidos em estudo conduzido em granjas de suínos na região metropolitana de Recife, onde apenas 2,4\% dos animais foram positivos ao 2-ME (Ribeiro et al., 2000). Entretanto, Silva et al. (2009) não detectaram animais soropositivos para Brucella spp. ao estudarem matrizes e reprodutores suínos de granjas de sistema de produção intensivo do estado de Alagoas. Vale ressaltar que as granjas reprodutoras de suídeos certificadas devem ser livres de brucelose, como também de pseudorraiva e PSC (Brasil, 2009).

Anticorpos anti-Brucella spp. não foram detectados nos suínos de criações extensivas, semelhantemente ao observado por Aguiar et al. (2006), que, ao estudarem suínos de agricultura familiar no estado de Rondônia, detectaram apenas um suíno soropositivo ao AAT, 0,9\% (1/104), porém esta amostra não reagiu ao 2-ME. De maneira inversa, estudo realizado por um grupo paraense demonstrou alta soroprevalência de Brucella spp. em suínos de abate clandestino, com 42,2\% (59/139) dos animais sororreagentes (Freitas et al., 2001). A despeito da baixa soroprevalência para Brucella spp. em suínos no Piauí, é importante ressaltar a necessidade de ações e medidas de vigilância sanitária que reprimam a atividade clandestina de abate de animais para consumo humano, uma vez que a brucelose suína já foi considerada a principal fonte de infecção para humanos no Brasil (Lima, 2010).

\section{CONCLUSÕES}

A detecção de anticorpos para o vírus da pseudorraiva em suínos de criação extensiva enfatiza a necessidade de adoção de estratégias de controle da enfermidade nessa subpopulação, os quais são potenciais fontes de infecção para suínos de produção intensiva, bem como outras espécies domésticas. Apesar das baixas soroprevalências de Brucella spp. e vírus da peste suína clássica, ressalta-se a necessidade de triagem regular das enfermidades de notificação obrigatória na população suídea do estado, possibilitando a adoção de medidas de prevenção e controle da infecção, quando necessário. Finalmente, é preciso ressaltar a importância de controle do abate clandestino no estado, uma vez que esta prática inviabiliza o reconhecimento de enfermidades disseminadas entre as populações suínas.

\section{AGRADECIMENTOS}

À Coordenação de Aperfeiçoamento de Pessoal de Nível Superior (Capes), pelo apoio financeiro; ao Programa Nacional de Cooperação Acadêmica (Procad) entre UFMG e UFPI; ao Instituto Nacional de Ciência e Tecnologia (INCT) de Informação Genético-Sanitária da Pecuária Brasileira; ao professor Dr. Fernando Aécio de Amorim Carvalho, pelo suporte técnico e laboratorial para realização dos exames; aos produtores de suínos e funcionários da UFPI, pela colaboração com a coleta das amostras deste estudo. R.M.C. Guedes é bolsista de produtividade em pesquisa do $\mathrm{CNPq}$.

\section{REFERÊNCIAS}

AGUIAR, D.M.; CAVALCANTE, G.T.; DIB, C.C. et al. Anticorpos contra agentes bacterianos e virais em suínos de agricultura familiar do município de monte negro, RO. Arq. Inst. Biol., v.73, p.415-419, 2006.

ALTON, G.G.; JONES, L.M.; ANGUS, R.D.; VERGER J.M. Techniques for the brucellosis laboratory. Paris: Institut National de la Recherche Agronomique, 1988. 188p.

ANÁLISIS Cronológico PPC. Paris: Organização Mundial de Sanidade Animal, 2008. Disponível em: <http://www.oie.int/wahis/public.php?page=cou ntry_disease_time_series\&disease_id=13\&diseas e_type=Terrestrial\&selected_analysis=tot_new\& selected_start_month $=1 \&$ selected_start_year $=20$ 08\&selected_end_month $=12 \&$ selected_end_year =2008> . Acessado em: 27 mar. 2011 .

BASCUÑANA， C.R.; BJÖRNEROT, L.; BALLAGI-PORDÁNY, A. et al. Detection of pseudorabies virus genomic sequences in apparently uninfected "single reactor" pigs. Vet. Microbiol., v.55, p.37-47, 1997.

BLOME, S.; MEINDL-BÖHMER, A.; LOEFFEN, W. et al. Assessment of classical swine fever diagnostics and vaccine performance. Rev. Sci. Tech., v.25, p.1025-38, 2006. 
BRASIL, Ministério da Agricultura, Pecuária e Abastecimento. Manual de Legislação: Programas Nacionais de Saúde Animal do Brasil. Brasília: MAPA/SDA/DSA, 2009. 440p.

BRASIL. MAPA. Brasília: Ministério da Agricultura Pecuária e Abastecimento Animal/espécies/suínos, 2011. Disponível em: $<$ http://www.agricultura.gov.br/portal/page/porta 1/Internet-MAPA/pagina-inicial/animal/especies/ suinos>. Acessado em: 27 mar. 2011.

CLASSICAL Swine Fever. Iowa: The Center for Food Security and Public Health, 2007. Disponível em: <http://www.cfsph.iastate.edu/ Factsheets/pdfs/classical_swine_fever.pdf $>$.

Acessado em: 27 mar. 2011.

FERRER, E.; FONSECA, O.; PERCEDO, M.I; ABELEDO, M.A. La Peste Porcina Clásica en las Américas y el caribe. Actualidad y perspectivas de control y erradicación. Rev. Salud Anim., v.32, p.11-21, 2010.

FONSECA JÚNIOR, A.A. Epidemiologia molecular de amostras brasileiras do vírus da doença de Aujeszky. 2008. 53f. Dissertação (Mestrado em Ciência Animal) - Escola de Veterinária, Universidade Federal de Minas Gerais, Belo Horizonte.

FREITAS, J.A.; GALINDO, G.A.R.; SANTOS, E.J.C. et al. Risco de brucelose zoonótica associado a suínos de abate clandestino. Rev. Saud. Pub., v.35, p.101-102, 2001.

GOMES, A.S. Programa Nacional de Sanidade Suídea (PNSS). Brasil: Ministério da Agricultura, Pecuária e Abastecimento, 2009. 441p.

JUNGERSEN, G.; SØRENSEN, V.; GIESE, S.B. et al. Differentiation between serological responses to Brucella suis and Yersinia enterocolitica 0:9 after natural or experimental infection in pigs. Epidemiol. Infect., v.134, p.347-357, 2006.

LIMA, E.S. Diagnóstico sorológico de doenças infecciosas causadoras de falhas reprodutivas em suínos. 2010. 130f. Dissertação (Mestrado em Ciência Animal) - Centro de Ciências Agroveterinárias, Universidade do Estado de Santa Catarina, Lages.

LOPES, L.B.; NICOLINO, R.; HADDAD, J.P.A. Brucellosis - Risk Factors and Prevalence: A Review. Op. Vet. Sci. J., v.4, p.72-84, 2010.
MANUAL of diagnostic tests and vaccines for terrestrial animals. 5.ed. Paris: Organização Mundial de Sanidade Animal, 2009. Disponível em: <http://www.oie.int/eng/normes/mmanual/A _summry.htm> Acessado em: 25 mar. 2011.

MAXIE, M.G.; YOUSSEF, S. Nervous system. In: MAXIE, M.G. (Ed.). Jubb, Kennedy, and Palmer's pathology of domestic animals. 5.ed. Philadelphia: Elsevier, 2007. p.281-457.

MEJIA, R. Procedimientos para estúdios de prevalencia de enfermidades cronicas en el ganado. Buenos Aires: Centro Panamericano de Zoonoses, 1973. 33p.

MOTTA, P.M.C.; FONSECA Jr., A.A.; OLIVEIRA, A.M. et al. Inquérito soroepidemiológico para brucelose em suídeos do Brasil. Vet. Foco, v.7, p.141-147, 2010.

MURPHY, F.A.; FAUQUET, C.M.; BISHOP, D.H.L. et al. Virus Taxonomy: Classification and Nomenclature of Viruses. New York: SpringerVerlag, 1995. 586p.

ORGANIZACIÓN Internacional de La Salud. Comité mixto FAO/OMS de expertos en brucelosis (série de informes técnicas, 740). Genebra: OMS, 1986. 149p.

OSLEN, S.C. Brucellosis in the United States: Role and significance of wildlife reservoirs. Vaccine, v.28, p.73-76, 2010.

POESTER, F.P.; GONÇALVES, V.S.P.; LAGE, A.P. Brucellosis in Brazil. Vet. Microbiol., v.90, p.55-62, 2002.

POMERANZ, L.E.; REYNOLDS, A.E.; HENGARTNER, C.J. Molecular biology of pseudorabies virus: impact on neurovirology and veterinary medicine. Microbiol. Mol. Biol. Rev., v.69, p.462-500, 2005.

PORCINE and Rangiferine Brucellosis. Iowa: The Center for Food Security and Public Health, 2007. Disponível em: <http://www.cfsph.iastate.edu/Factsheets/pdfs/br ucellosis_suis.pdf $>$. Acessado em: 27 mar. 2011.

PRAUD, A.; GIMENEZ, O.; ZANELLA, G. et al. Estimation of sensitivity and specificity of five serological tests for the diagnosis of porcine brucellosis. Prev. Vet. Med., v.104, p.94-100, 2012. 
RIBEIRO, T.C.F.S.; MOTA, R.A.; COSTA, A.N. et al. Inquérito soroepidemiológico da brucelose suína em granjas comerciais da região metropolitana do Recife - PE. Cienc. Vet. Trop., v.3, p.135-143, 2000.

SANTOS, R.L. Peste suína clássica. International Veterinary Medicine, College of Veterinary Medicine, University of Georgia, 2002. Disponível em: <http://www.vet.uga.edu/vpp/archives/IVM/POR T/csf/index.php> Acessado em: 20 out. 2011.

SÃO PAULO. Diagnóstico da situação da doença de Aujeszky no Estado de São Paulo. Campinas: CATI, 1986. 75p.
SILVA, M.A.; SOUZA, L.C.A.; SANTANA, F.C. et al. Inquérito soroepidemiológico da infecção por Brucella spp. em granjas suinícolas tecnificadas no Estado de Alagoas. In: ENCONTRO INTERNACIONAL DE PRODUÇÃO CIENTÍFICA CESUMAR, 6., 2009, Maringá. Anais... Paraná: [s.n.] 2009. p.1-4. (Resumo).

SOUZA, L.M.; SOBESTIANSKY, J.; MATOS, M.P.C.; CAIADO, K.L. Prevalência da infecção pelo vírus da doença de Aujeszky em matrizes de sistemas de produção que abastecem o mercado consumidor de Goiânia. Cienc. Anim. Bras., v.3, p.53-56, 2002. 